\title{
Predicting survival in pulmonary arterial hypertension in the UK
}

\author{
Wai-Ting Nicola Lee*, Yi Ling*, Karen K. Sheares*, Joanna Pepke-Zaba\#, \\ Andrew John Peacock* and Martin Keith Johnson*
}

ABSTRACT: Contemporary prognostic equations in pulmonary arterial hypertension (PAH) derived from US and French cohorts may not perform as well in the UK as a locally derived scoring scheme. The aim of the study was to develop and validate a UK risk score to predict prognosis in PAH.

Baseline mortality predictors identified by multivariate Cox analysis in 182 incident PAH patients were used to derive the Scottish composite score (SCS). Its prognostic performance in an independent UK cohort was compared with the French registry and Pulmonary Hypertension Connection (PHC) registry equations using Brier scores (BS).

The SCS based on age, sex, aetiology, right atrial pressure, cardiac output and 6-min walk distance predicted survival in the validation cohort (hazard ratio (HR) 1.7 per point increase; $\mathbf{p}<\mathbf{0 . 0 0 1}$ ) and provided further prognostic stratification in World Health Organization (WHO) functional class III patients (HR 1.8 per point increase; $\mathbf{p}<\mathbf{0 . 0 0 1}$ ). It was more accurate than the French registry equation in predicting $1-y r$ survival (BS: 0.092 versus $0.146 ; p=0.001$ ) and 2-yr survival $(0.131$ versus $0.255 ; p<0.001)$. There was no significant difference in BS between the SCS and PHC registry equation.

The SCS predicts survival and can be used to supplement WHO functional class in prognostication.

KEYWORDS: Prognosis, pulmonary hypertension, survival

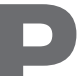
ulmonary arterial hypertension (PAH) remains an incurable disease associated with high morbidity and mortality despite expansion of effective pharmacological therapy in the last decade [1]. As accurate prognostication is an integral part of disease management, considerable efforts have been made to identify prognostic factors and develop algorithms to predict patient outcome for clinical use. The first prognostic equation based on pulmonary haemodynamics (right atrial pressure (Pra)), mean pulmonary artery pressure (mean $P$ pa) and cardiac index at diagnosis) was derived from the National Institutes of Health (NIH) registry study of 194 patients with primary pulmonary hypertension (now classified as idiopathic, heritable and anorexigen-associated $\mathrm{PAH}$ ) from 32 centres across the USA two decades ago before the advent of PAH-specific drug therapy [2]. It has become obsolete but continues to be used as a benchmark for patient outcome without targeted therapeutic intervention. Survival analysis of a contemporary PAH cohort from the Pulmonary
Hypertension Connection (PHC) registry treated in a single centre in Chicago (IL, USA), including demographics and functional measures, identified the same haemodynamic variables as the NIH equation and these were used to derive a new equation based on a similar methodological approach [3]. Another prognostic equation based on sex, 6-min walk distance (6MWD) and cardiac output (CO) has been developed from the French registry including incident and prevalent patients diagnosed up to 3 yrs prior to study entry $[4,5]$. These two contemporary equations only apply to patients with idiopathic, familial and anorexigen-associated $\mathrm{PAH}$ whereas the equation developed from the Registry to Evaluate Early and Long-term Pulmonary Arterial Hypertension Disease Management (REVEAL) included all patients in World Health Organization (WHO) Group I PAH [6]. Due to its large sample size, a greater number of variables were incorporated in the prediction model compared with the French registry and PHC registry equations (13 versus three variables).
AFFILIATIONS

*Scottish Pulmonary Vascular Unit, Golden Jubilee National Hospital, Glasgow, and

\#Pulmonary Vascular Disease Unit, Papworth Hospital NHS Foundation Trust, Cambridge, UK.

\section{CORRESPONDENCE}

M.K. Johnson

Scottish Pulmonary Vascular Unit, Level 1

Golden Jubilee National Hospital Agamemnon Street

Clydebank

Glasgow

G81 4DY

UK

E-mail: mjohnson4@nhs.net

Received:

Nov 112011

Accepted after revision:

March 242012

First published online:

May 032012 
These contemporary prognostic algorithms utilise baseline variables to calculate a predicted probability of survival at a certain time point during follow-up. Validation data on these equations published so far support their predictive value. The REVEAL equation and its simplified risk score (a 22-point scoring system) have been shown to have good discriminatory ability in a prospective PAH cohort of newly diagnosed patients [7]. When the PHC registry and French registry equations were applied to a prospective cohort of PAH patients followed up in four randomised controlled clinical trials and their extension studies, there was good agreement between predicted and observed survival [8]. As these equations were developed from patient populations in the USA and France with differing demographics, healthcare systems and treatment approaches to the UK, they may not perform as well in UK PAH populations as a locally derived scoring scheme. The aims of this study were to develop a UK risk score to predict prognosis in $\mathrm{PAH}$ patients from a well-defined cohort in Scotland, and to validate its prognostic performance against other published prognostic equations in an independent UK PAH cohort.

\section{METHODS}

\section{Study design}

A retrospective cohort of incident and treatment naïve patients diagnosed with WHO Group I PAH in the Scottish Pulmonary Vascular Unit (Glasgow, UK) between November 2000 and September 2009 were used to derive the Scottish composite score (SCS). Exclusion criteria were PAH associated with congenital heart disease (CHD-PAH), long-term calcium channel blocker $(\mathrm{CCB})$ responders, pulmonary capillary wedge pressure $\left(\mathrm{Ppw}_{\mathrm{pcw}}\right)$ $>15 \mathrm{mmHg}$ and significant lung disease (defined by forced expiratory volume in $1 \mathrm{~s}$ or forced vital capacity or total lung capacity $<60 \%$ predicted based on the European Coal and Steel Community reference values) [9]. The diagnosis of $\mathrm{PAH}$ was based on right heart catheterisation (RHC) in accordance with contemporary guidelines $[1,10]$. Patients were subsequently treated with conventional therapy (long-term warfarin, diuretics or supplemental oxygen) and $\mathrm{PAH}$-specific monotherapy (prostacyclin analogues, phosphodiesterase- 5 inhibitors or endothelin receptor antagonists). Sequential combination therapy was initiated as clinically indicated. Baseline data on demographics, RHC, lung function, WHO functional class (FC), 6MWD, N-terminal-pro-brain natriuretic peptide (NT-pro-BNP) and Cambridge Pulmonary Hypertension Outcome Review (CAMPHOR) score [11] recorded within 3 months of diagnostic RHC and prior to starting PAH-specific therapy were collected. The variables found to be independent mortality predictors in multivariate Cox analysis were included in the SCS. Weighted points were assigned to the threshold values of each variable identified by exploratory analysis. The SCS was obtained by summation of the points scored for each variable and finalised prior to validation in a cohort of incident and treatment naive idiopathic and heritable PAH patients treated in the Pulmonary Vascular Disease Unit at Papworth Hospital (Cambridge, UK) between January 2001 and December 2009. Patients with significant lung disease (defined by lung function), raised $P$ pcw and long-term CCB responders were excluded. Baseline data were collected to apply the SCS, French registry and PHC registry equations. The ability of the SCS to predict survival over time and stratify patients into prognostic groups in the whole cohort and in WHO FC III patients was tested. The French registry and PHC registry equations were used to compute survival estimates at 1 and 2 yrs post-diagnosis. Their predictive accuracy was compared with that of the SCS using the Brier score (BS). Patient consent was considered unnecessary by the local research ethics committee in the respective institutions.

\section{Statistical analysis}

Statistical analysis was performed using Statview version 5.0.1 (SAS Institute, Cary, NC, USA) and Graphpad Prism version 5.00 (Graphpad Software, La Jolla, CA, USA). Continuous variables were checked for normality using a D'Agostino and Pearson omnibus normality test. Normally distributed variables were described using the mean and standard deviation, and compared using an unpaired t-test. Non-normally distributed variables were described using the median and interquartile range and compared using Mann-Whitney U test. Categorical variables were described using number (percentage) and compared by the Chi-squared test.

Univariate Cox proportional hazards analysis was used to identify baseline mortality predictors in the derivation cohort. Survival time was calculated from the date of RHC to the date of data cut-off (May 1, 2010). Patients who received lung transplantation or were lost to follow-up were censored on the date of procedure or last clinical contact. Significant continuous variables were transformed into categorised variables using threshold values identified in exploratory Cox analysis (see online supplementary data) and were assessed with their corresponding indicator variable coding for missing data ("missing" and "not missing") in a multivariate Cox model using a backward selection procedure. The use of indicator variables was to allow inclusion of patients with missing data in multivariate analyses. None of the indicator variables for missing data was predictive of survival. Sex was not significant in univariate Cox analysis but was entered in the multivariate model as its prognostic significance has been confirmed in previous studies. Aetiology was divided into two subgroups: connective tissue disease associated pulmonary arterial hypertension due to systemic sclerosis (CTD-PAH-SSc) and WHO Group I PAH others versus idiopathic, heritable, anorexigen-associated and CTD-PAH non-SSc (reference subgroup). Anorexigen-associated PAH was included in the reference subgroup as these patients are regarded as having similar outcomes to those with idiopathic and heritable PAH. "WHO Group I PAH others" included patients with portopulmonary hypertension, HIV and pulmonary veno-occlusive disease. Variables with $\mathrm{p}<0.1$ were retained in the final multivariate Cox model. Weighted points were assigned to each variable subgroup according to their adjusted hazard ratio (HR) in the final model, for example, 0 point was assigned to the reference subgroup with an adjusted HR of 1 . For the other subgroups, 1 point was assigned if the adjusted HR was 2, 2 points if the adjusted HR was 3 and 3 points if the adjusted HR was 4.

Kaplan-Meier analysis was used to estimate survival rates and comparison between groups was made by the log-rank test for trend. Cox analysis was used to evaluate the ability of the SCS to predict survival in the validation cohort. The BS $[12,13]$ was used to assess the accuracy of the SCS, French registry and $\mathrm{PHC}$ registry equations in predicting 1- and 2-yr survival in the validation cohort allowing for censoring. It measures the mean squared deviation of predicted probability from the actual 
outcome. A BS of 0 indicates perfect prediction. A BS of 0.25 indicates that the prediction is equivalent to the outcome occurring by chance alone. Higher prediction accuracy is indicated by a lower BS. To compare the performance of the SCS with other equations, a point estimate of difference in BS between SCS and each equation and its 95\% confidence interval was obtained from 200,000 bootstrap re-samples. A difference in BS of $>0.02$ was considered clinically relevant. A p-value $<0.05$ was defined as statistically significant.

\section{RESULTS}

\section{Derivation of the SCS}

Characteristics of the derivation cohort and the aetiology reference subgroup are summarised in table $1.10 \%$ of patients received prostacyclin analogues (7\% intravenous epoprostenol, $2 \%$ inhaled iloprost, $1 \%$ subcutaneous treprostinil), $47 \%$ phosphodiesterase- 5 inhibitors ( $45 \%$ sildenafil $45 \%$ and $2 \%$ tadalafil) and $44 \%$ endothelin receptor antagonists (29\% bosentan, $7 \%$ sitaxentan and $8 \%$ ambrisentan). After a median follow-up period of 25 months (range $0.1-113$ months), 81 patients died from all causes, two patients received lung transplantation, one patient was lost to follow-up and two patients transferred care to another centre. The survival estimates for the whole cohort were $79 \%$ at $1 \mathrm{yr}, 68 \%$ at $2 \mathrm{yrs}$ and $57 \%$ at $3 \mathrm{yrs}$. Out of the 17 baseline variables considered in the univariate Cox model, age, aetiology, carbon monoxide diffusing capacity \% pred, Pra, CO, WHO FC, 6MWD, NT-pro-BNP and CAMPHOR score were significant mortality predictors (table 2 ). When these variables

\section{TABLE 1 Baseline characteristics of the derivation cohort (all patients versus patients in the aetiology reference subgroup)}

\begin{tabular}{|c|c|c|c|}
\hline & All patients & Aetiology reference subgroup & p-value \\
\hline Subjects $n$ & 182 & 125 & \\
\hline Females & $125(69)$ & $81(65)$ & 0.477 \\
\hline \multicolumn{4}{|l|}{ Aetiology } \\
\hline Idiopathic PAH & $97(53)$ & $97(78)$ & \\
\hline SSc associated & $33(18)$ & & \\
\hline non-SSc associated & $26(14)$ & $26(21)$ & \\
\hline \multicolumn{4}{|l|}{ WHO Group I PAH others } \\
\hline $\mathrm{PoPH}$ & $15(8)$ & & \\
\hline HIV & $1(0.5)$ & & \\
\hline PVOD & $8(4)$ & & \\
\hline \multicolumn{4}{|c|}{ Pulmonary haemodynamics } \\
\hline Pra $\mathrm{mmHg}$ & $7(4-11)$ & $6(4-10)$ & 0.421 \\
\hline Mean Ppa mmHg & 47 (39-55) & $48(40-58)$ & 0.459 \\
\hline $\mathrm{CO} \mathrm{L} \cdot \mathrm{min}^{-1}$ & $3.6(2.9-4.7)$ & $3.6(2.9-4.7)$ & 0.929 \\
\hline PVR Wood units & $10.8(7.4-15.5)$ & $11.2(7.6-15.7)$ & 0.596 \\
\hline $\mathrm{Sv}, \mathrm{O}_{2} \%$ & $64(57-70)$ & $65(58-70)$ & 0.789 \\
\hline \multicolumn{4}{|l|}{ WHO FC } \\
\hline | and || & $25(14)$ & $19(15)$ & 0.899 \\
\hline III & $131(72)$ & $87(70)$ & \\
\hline IV & $26(14)$ & $19(15)$ & \\
\hline 6MWD m & $260 \pm 109^{+}$ & $273 \pm 110^{++}$ & 0.342 \\
\hline
\end{tabular}

Data are expressed as median (interquartile range), $n$ (\%) or mean $\pm \mathrm{SD}$, unless otherwise stated. PAH: pulmonary arterial hypertension; CTD-PAH: connective tissue disease associated PAH; SSc: systemic sclerosis; WHO: World Health Organization; PoPH: portopulmonary hypertension; PVOD: pulmonary veno-occlusive disease; FEV1: forced expiratory volume in $1 \mathrm{~s}$; FVC: forced vital capacity; $D \mathrm{~L}, \mathrm{CO}$ : diffusing capacity of the lung for carbon monoxide; Pra: right atrial pressure; Ppa: pulmonary artery pressure; $\mathrm{CO}$ : cardiac output; PVR: pulmonary vascular resistance; $\mathrm{S}, \mathrm{vO}_{2}$ : mixed venous saturation; FC: functional class; 6MWD: 6-min walk distance; NT-pro-BNP:

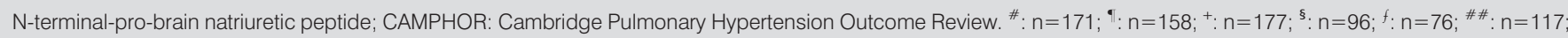
"ฯ: $n=108 ;{ }^{++}: n=122 ;{ }^{\text {ss: }} \mathrm{n=63;}{ }^{f f}: \mathrm{n}=51$. 


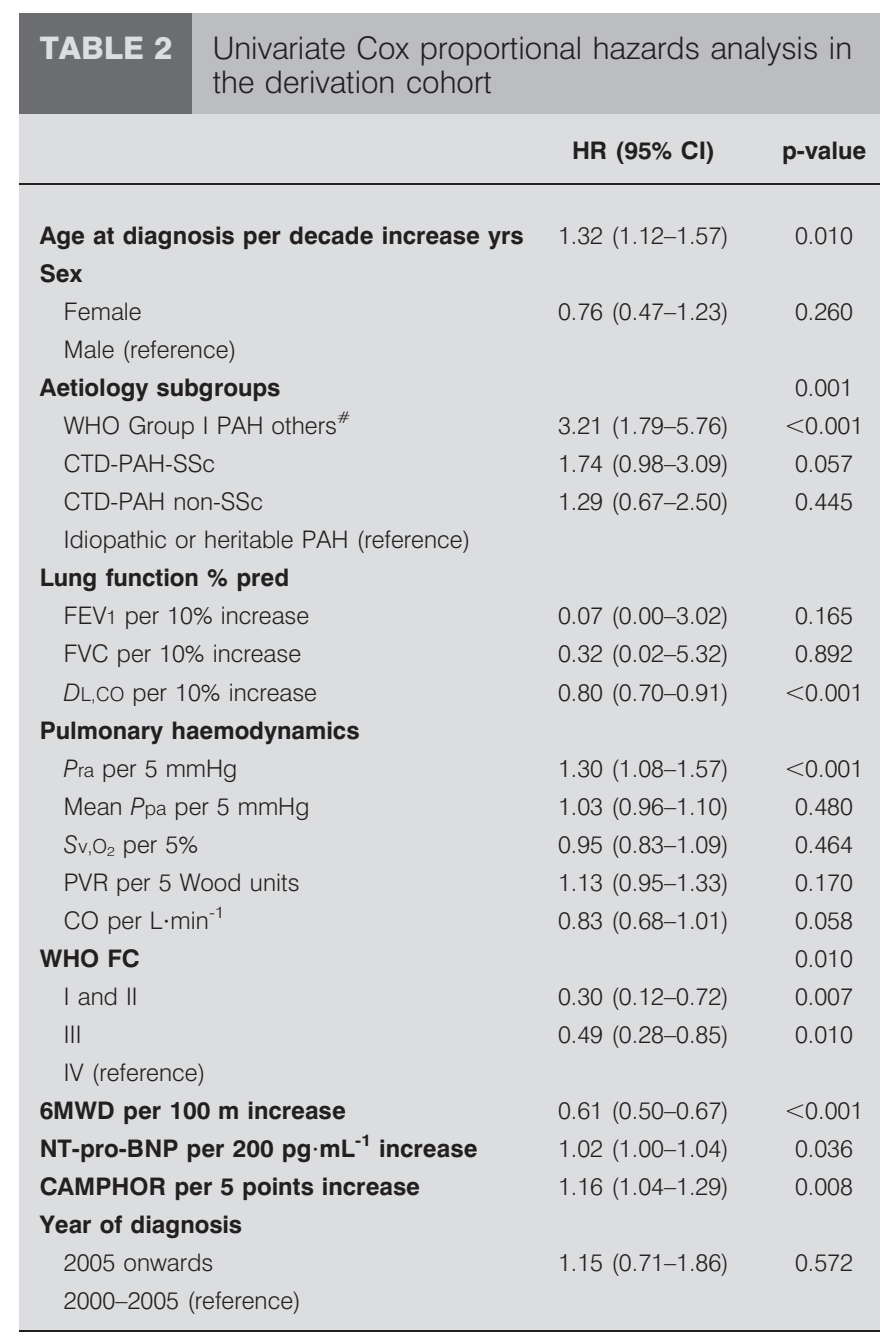

WHO: World Health Organization; PAH: pulmonary arterial hypertension; CTDPAH: connective tissue disease associated PAH; SSc: systemic sclerosis; FEV1: forced expiratory volume in $1 \mathrm{~s}$; FVC: forced vital capacity; $\mathrm{LL,CO}$ : diffusing capacity of the lung for carbon monoxide; Pra: right atrial pressure; Ppa: pulmonary artery pressure; $\mathrm{Sv}_{1} \mathrm{O}_{2}$ : mixed venous saturation; PVR: pulmonary vascular resistance; $\mathrm{CO}$ : cardiac output; FC: functional class; 6MWD: 6-min walk distance; NT-pro-BNP: N-terminal-pro-brain natriuretic peptide; CAMPHOR:

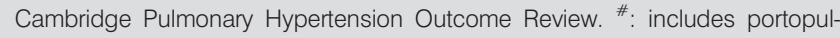
monary hypertension, HIV and pulmonary veno-occlusive disease.

were categorised into two to four subgroups and assessed in a multivariate Cox model, age at diagnosis, sex, aetiology, Pra, CO and 6MWD were retained as independent mortality predictors and were used to construct the SCS (0 to 8) (table 3).

\section{Validation of the SCS}

Out of 119 patients in the validation cohort, 99 patients had complete data to calculate the SCS (table 4). 38 patients died and four received lung transplantation during follow-up (median 29 months, range 0.3-102 months). The 1-, 2- and 3yr survival estimates for patients in whom SCS was available were 87,74 and $68 \%$, respectively which were not significantly different from those in whom SCS was not available (log-rank $p=0.196$ ). The risk of death increased with the SCS (HR 1.7 per

\begin{tabular}{|c|c|c|c|}
\hline TABLE 3 & \multicolumn{3}{|c|}{$\begin{array}{l}\text { Multivariate mortality predictors and derivation of } \\
\text { the Scottish composite score }\end{array}$} \\
\hline Variables & Categories & $\begin{array}{c}\text { Adjusted HR } \\
\qquad(95 \% \mathrm{Cl})\end{array}$ & Points \\
\hline \multirow[t]{2}{*}{ Age yrs } & $\geqslant 70$ & $2.20(1.35-3.61)$ & 1 \\
\hline & $<70$ (reference) & & 0 \\
\hline \multirow[t]{2}{*}{ Sex } & Male & $2.01(1.15-3.51)$ & 1 \\
\hline & Female (reference) & & 0 \\
\hline \multirow[t]{2}{*}{ Aetiology } & $\begin{array}{l}\text { CTD-PAH-SSc or Group } \\
\text { I PAH others }{ }^{\#}\end{array}$ & $2.33(1.42-3.82)$ & 1 \\
\hline & $\begin{array}{l}\text { Idiopathic, heritable, anorexigen- } \\
\text { associated PAH or } \\
\text { CTD-PAH non-SSc }\end{array}$ & & 0 \\
\hline \multirow[t]{4}{*}{ 6MWD m } & $<50$ & $5.04(2.33-10.89)$ & 3 \\
\hline & 50-149 & $3.45(1.48-8.05)$ & 2 \\
\hline & 150-299 & $2.48(1.28-4.79)$ & 1 \\
\hline & $\geqslant 300$ (reference) & & 0 \\
\hline \multirow[t]{2}{*}{ Pra $\mathrm{mmHg}$} & $\geqslant 10$ & $1.50(0.90-2.49)$ & 1 \\
\hline & $<10$ (reference) & & 0 \\
\hline \multirow[t]{2}{*}{$\mathrm{CO} L \cdot \mathrm{min}^{-1}$} & $<3$ & $2.18(1.32-3.61)$ & 1 \\
\hline & $\geqslant 3$ (reference) & & 0 \\
\hline
\end{tabular}

6MWD: 6-min walk distance; Pra: right atrial pressure; CO: cardiac output; CTD$\mathrm{PAH}$ : connective tissue disease associated pulmonary arterial hypertension (PAH); SSc: systemic sclerosis; ${ }^{\#}$ : includes portopulmonary hypertension, HIV and pulmonary veno-occlusive disease.

point increase, 95\% CI 1.4-2.1, $\mathrm{p}<0.001)$. When patients were stratified into three SCS risk groups ("high risk": 4-8 $(n=23)$; "intermediate risk": 2-3 ( $n=44)$; and "low risk": 0-1 $(n=32))$, there was a significant difference in survival between groups $(\mathrm{p}<0.001$ by log-rank test for trend) (fig. 1). The SCS further stratified WHO FC III patients (HR 1.8 per point increase, 95\% CI 1.4-2.4, $\mathrm{p}<0.001)(\mathrm{n}=66,30$ deaths). When these patients were stratified into three SCS risk groups ("high risk" $=4-8$, "intermediate risk" = 2-3, "low risk" = 0-1), there was a significant difference in survival between groups $(\mathrm{p}<0.001$ by log-rank test for trend) (fig. 2).

\section{Comparison of prognostic equations}

When the SCS, French registry and PHC registry equations were applied to the validation cohort to predict 1- and 2-yr survival, the SCS had a lower BS than both equations but only the comparison with the French registry equation reached statistical significance (table 5).

\section{DISCUSSION}

The present study is the first to describe the derivation and validation of a risk score to predict prognosis in incident patients with PAH based on UK data. The data analysis showed that the SCS, an 8-point simple scoring system based on age, sex, aetiology, Pra, CO and 6MWD at diagnosis, can be used to categorise patients into prognostic groups and provide further risk stratification in WHO FC III patients. When tested in an independent UK PAH cohort, the predictive accuracy of the SCS was comparable to that of the PHC registry equation and may be greater than the French registry equation. The 


\begin{tabular}{|c|c|c|c|}
\hline & Derivation cohort & Validation cohort & $p$-value \\
\hline Subjects $\mathrm{n}$ & 182 & 99 & \\
\hline Age yrs & $62(48-73)$ & 53 (42-69) & 0.010 \\
\hline Females & $125(69)$ & $72(73)$ & 0.479 \\
\hline \multicolumn{4}{|l|}{ Aetiology } \\
\hline Idiopathic PAH & $97(53)$ & $96(97)$ & \\
\hline Heritable PAH & $2(1)$ & $3(3)$ & \\
\hline \multicolumn{4}{|l|}{ CTD-PAH } \\
\hline SSc associated & $33(18)$ & & \\
\hline non-SSc associated & $26(14)$ & & \\
\hline \multicolumn{4}{|c|}{ WHO Group I PAH others } \\
\hline $\mathrm{PoPH}$ & $15(8)$ & & \\
\hline HIV & $1(0.5)$ & & \\
\hline PVOD & $8(4)$ & & \\
\hline \multicolumn{4}{|l|}{ Lung function \% pred } \\
\hline FEV 1 & $87(75-98)^{\#}$ & $84 \pm 15$ & 0.038 \\
\hline FVC & $99(86-112)^{\#}$ & $97 \pm 17$ & 0.094 \\
\hline$D\llcorner, C O$ & $42(28-60)^{\pi}$ & $59 \pm 22^{\# \#}$ & $<0.001$ \\
\hline \multicolumn{4}{|c|}{ Pulmonary haemodynamics } \\
\hline Pra mmHg & $7(4-11)$ & $9 \pm 6$ & 0.013 \\
\hline Mean Ppa mmHg & 47 (39-55) & $50(42-59)$ & 0.016 \\
\hline $\mathrm{CO} L \cdot \mathrm{min}^{1}$ & $3.6(2.9-4.7)$ & $3.2(2.6-3.8)$ & 0.002 \\
\hline PVR Wood units & $10.8(7.4-15.5)$ & $13.3 \pm 5.4$ & 0.011 \\
\hline $\mathrm{Sv}, \mathrm{O}_{2} \%$ & $64(57-70)$ & $63 \pm 8$ & 0.889 \\
\hline \multicolumn{4}{|l|}{ WHO FC } \\
\hline | and || & $25(14)$ & $18(18)$ & 0.572 \\
\hline III & $131(72)$ & $66(67)$ & \\
\hline IV & $26(14)$ & $15(15)$ & \\
\hline 6MWD m & $260 \pm 109^{+}$ & $267 \pm 121$ & 0.669 \\
\hline NT-pro-BNP pg $\cdot \mathrm{mL}^{-1}$ & $1026(298-2637)^{\S}$ & $2029(330-4407)^{\text {ศ๘ }}$ & 0.134 \\
\hline CAMPHOR & $38(27-57)^{f}$ & $38(26-57)^{++}$ & 0.804 \\
\hline \multicolumn{4}{|l|}{ Year of diagnosis } \\
\hline Prior to 2005 & $51(28)$ & $45(45)$ & 0.003 \\
\hline 2005 onwards & $131(72)$ & $54(55)$ & \\
\hline
\end{tabular}

Data are expressed as median (interquartile range), $\mathrm{n}(\%)$ or mean $\pm \mathrm{SD}$, unless otherwise stated. PAH: pulmonary arterial hypertension; CTD-PAH: connective tissue disease associated PAH; SSc: systemic sclerosis; WHO: World Health Organization; PoPH: portopulmonary hypertension; PVOD: pulmonary venoocclusive disease; FEV ${ }_{1}$ : forced expiratory volume in $1 \mathrm{~s}$; FVC: forced vital capacity; $D \mathrm{~L}, \mathrm{CO}$ : diffusing capacity of the lung for carbon monoxide; Pra: right atrial pressure; Ppa: pulmonary artery pressure; CO: cardiac output; PVR: pulmonary vascular resistance; $\mathrm{Sv}, \mathrm{O}_{2}$ : mixed venous saturation; $\mathrm{FC}$ : functional class; 6MWD: 6 min walk distance; NTproBNP: N-terminal pro-brain natriuretic peptide; CAMPHOR: Cambridge Pulmonary Hypertension Outcome Review;

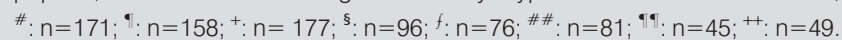

prognostic significance of sex and aetiology demonstrated by previous studies is also confirmed. These findings add to the growing body of literature on prognostication in $\mathrm{PAH}$ and provide further insights into the use of contemporary prognostic equations derived from other registry studies.

The predictive value of the French registry, PHC registry and REVEAL equations has been demonstrated in respective validation studies. However their applicability in other patient populations would be influenced by factors such as study

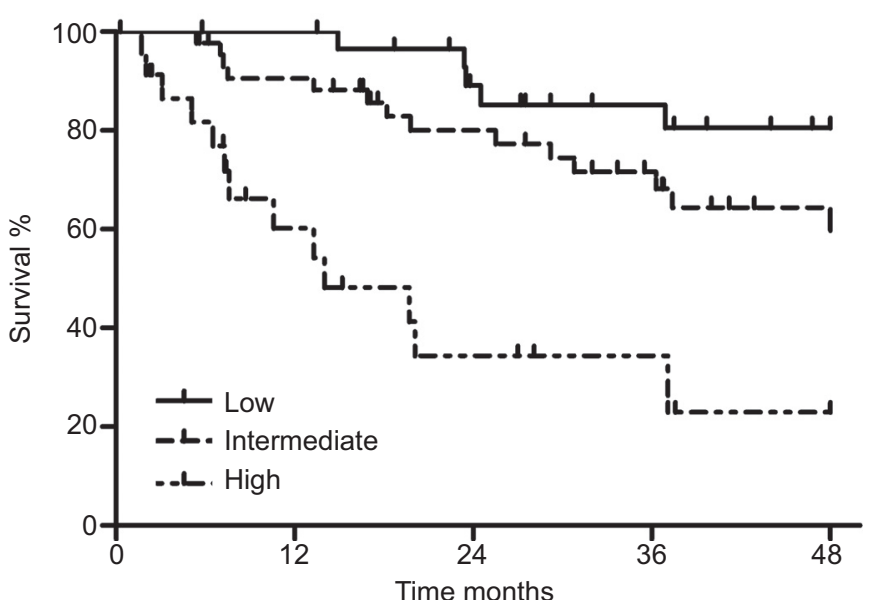

Patients at risk $n$

$\begin{array}{ccccc}32 & 31 & 24 & 19 & 13 \\ 44 & 39 & 30 & 23 & 14 \\ 23 & 11 & 6 & 4 & 1\end{array}$

FIGURE 1. Kaplan-Meier survival estimates of the validation cohort stratified by three Scottish composite score risk groups.

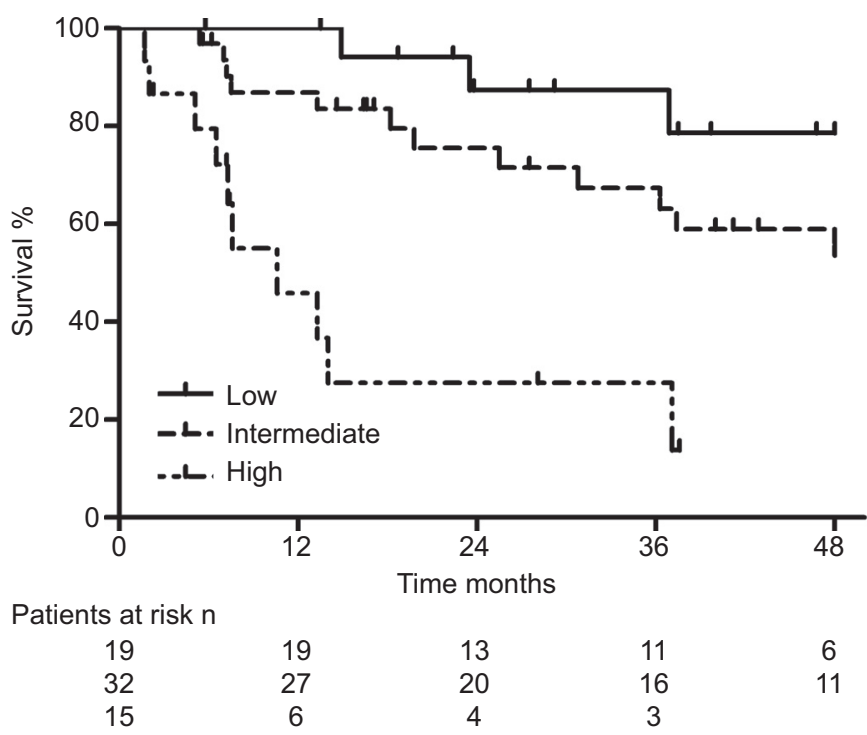

FIGURE 2. Kaplan-Meier survival estimates of World Health Organization functional class III patients in the validation cohort stratified by three Scottish composite score risk groups.

population characteristics, treatment pathways and statistical methodology (table 6). The SCS was designed as a simple point-based risk score to stratify patients into prognostic groups whereas the other equations were developed to compute predicted survival probabilities at certain time points post-diagnosis. Both SCS derivation and validation cohorts were treated in single tertiary centres and this would ensure complete data capture and uniformity of care. In contrast, the French registry and REVEAL included national cohorts from selected centres. This may lead to selection bias, variations in clinical practice and patient outcome. The SCS was derived from a strictly incident and treatment naive patient cohort, whereas French registry, PHC registry and REVEAL equations were derived from mixed 


\begin{tabular}{|c|c|c|c|}
\hline \multirow[t]{2}{*}{ TABLE 5} & \multicolumn{3}{|c|}{$\begin{array}{l}\text { Comparison of predictive accuracy between the } \\
\text { Scottish composite score (SCS) and other } \\
\text { published prognostic equations }\end{array}$} \\
\hline & & BS $(95 \% \mathrm{Cl})$ & $\mathrm{p}$-value \\
\hline \multicolumn{4}{|c|}{ Predicting 1-yr survival } \\
\hline French reg & try equation & $0.146(0.120-0.175)$ & \\
\hline PHC regist & equation & $0.111(0.060-0.168)$ & \\
\hline SCS & & $0.092(0.058-0.130)$ & \\
\hline Difference: & CS - French registry equation & $-0.055(-0.083--0.024)$ & 0.001 \\
\hline Difference: & $\mathrm{CCS}$ - PHC registry equation & $-0.019(-0.059-0.017)$ & 0.328 \\
\hline \multicolumn{4}{|c|}{ Predicting 2-yr survival } \\
\hline French reg & try equation & $0.255(0.210-0.302)$ & \\
\hline $\mathrm{PHC}$ regist & equation & $0.189(0.133-0.250)$ & \\
\hline scs & & $0.131(0.091-0.175)$ & \\
\hline Difference: & CS - French registry equation & $-0.124(-0.176--0.070)$ & $<0.001$ \\
\hline Difference: & $\mathrm{CS}$ - PHC registry equation & $-0.058(-0.122--0.002)$ & 0.060 \\
\hline
\end{tabular}

BS: Brier score; PHC: Pulmonary Hypertension Connection. A Brier Score of 0 indicates perfect prediction and 0.25 indicates a prediction equivalent to random chance.

incident and prevalent cohorts. The inclusion of prevalent patients would introduce survivor bias as these patients have survived long enough to be recruited in the study and would have a better prognosis than those who die early from severe disease or lack of response to PAH therapy. This was clearly demonstrated by comparing survival between incident and prevalent cohorts in the French registry study [5]. In order to remove this survivor bias, authors of the French registry equation estimated survival from time of diagnosis as opposed to time of enrolment and only considered patients to be at risk from their time of study entry. This adjustment for the time delay between diagnosis and study entry in prevalent patients was not adopted in the development of the PHC registry or REVEAL equations. The study period of the PHC registry spanned both pre- and post-modern treatment eras. Changes in patient prognosis over this period due to treatment advances are probable and this may have affected the survival analysis. These factors, in addition to variations in healthcare systems and treatment approaches, would impact on the performance of these prognostic algorithms in different clinical settings.

It is well recognised that patient outcome differs according to PAH aetiology. Patients with CHD-PAH were excluded from this study as they have a distinct haemodynamic profile and natural history from other PAH patients [14]. Pulmonary arterial hypertension associated with systemic sclerosis is known to confer a worse prognosis than idiopathic $\mathrm{PAH}$ despite a similar degree of haemodynamic derangement for reasons that are not fully understood $[15,16]$. When PAH associated with different types of connective tissue disease including mixed connective tissue disease, overlap syndromes and rheumatoid arthritis were grouped together and compared with CTD-PAH-SSc in the derivation cohort, CTD-PAH-SSc

TABLE 6 Prognostic algorithms in pulmonary arterial hypertension (PAH)

\begin{tabular}{|c|c|c|c|c|c|}
\hline $\begin{array}{l}\text { French registry } \\
\text { equation }[4,5]\end{array}$ & $\begin{array}{l}\text { Idiopathic, familial and } \\
\text { anorexigen-associated PAH } \\
\text { n=190, } 29 \% \text { incident and } \\
71 \% \text { prevalent cases }\end{array}$ & $\begin{array}{l}\text { 2002-2003, follow-up } \\
\text { time } 3 \text { yrs for all } \\
\text { patients }\end{array}$ & 6MWD, sex, CO & $\begin{array}{c}\text { Survival up to } 3 \text { yrs } \\
\text { post-diagnosis }\end{array}$ & $\begin{array}{l}\text { Prospective } \\
\text { validation in PAH } \\
\text { cohorts from } \\
\text { clinical trials }\end{array}$ \\
\hline $\begin{array}{l}\text { Pulmonary } \\
\text { Hypertension } \\
\text { Connection registry } \\
\text { equation [3] }\end{array}$ & $\begin{array}{l}\text { Idiopathic, familial and } \\
\text { anorexigen-associated PAH } \\
\mathrm{n}=282 \text {, incident and } \\
\text { prevalent cases }\end{array}$ & $\begin{array}{l}\text { 1991-2007, median } \\
\text { (interquartile range) } \\
\text { follow-up time } 3.9 \\
\text { (1.7-7.8) yrs, maximum } \\
\text { follow-up time } 16.6 \text { yrs }\end{array}$ & Pra, mean $\mathrm{Ppa}, \mathrm{Cl}$ & $\begin{array}{c}\text { Survival at number of } \\
\text { yrs post-diagnosis }\end{array}$ & $\begin{array}{l}\text { Prospective } \\
\text { validation in } \\
\text { PAH cohorts from } \\
\text { clinical trials }\end{array}$ \\
\hline $\begin{array}{l}\text { REVEAL registry } \\
\text { equation and } \\
\text { risk score }[6,7]\end{array}$ & $\begin{array}{l}\text { WHO Group I PAH } \\
n=2716,14 \% \text { incident and } \\
86 \% \text { prevalent cases }\end{array}$ & $\begin{array}{l}2006 \text { onwards, mean } \\
\text { follow-up time } 1.4 \text { yrs, } \\
\text { range } 0-2 \text { yrs }\end{array}$ & $\begin{array}{l}\text { Age, aetiology, sex, renal } \\
\text { insufficiency, SBP, HR, } \\
\text { WHO FC, 6MWD, BNP } \\
\text { or NT-pro-BNP, Pra, PVR, } \\
\text { ipresence of pericardial } \\
\text { effusion, \% pred DL,CO }\end{array}$ & 1-yr survival & $\begin{array}{l}\text { Prospective } \\
\text { validation in newly } \\
\text { diagnosed PAH } \\
\text { patients from } \\
\text { REVEAL }\end{array}$ \\
\hline
\end{tabular}

REVEAL: Registry to Evaluate Early and Long-term Pulmonary Arterial Hypertension Disease Management; 6MWD: 6-min walk distance; CO: cardiac output; Pra: right atrial pressure; Ppa: pulmonary artery pressure; Cl: cardiac index; WHO: World Health Organization; SBP: systolic blood pressure; HR: heart rate; FC: functional class; BNP: brain natriuretic peptide; NT-pro-BNP: N-terminal-pro BNP; PVR: pulmonary vascular resistance; DL,CO: diffusing capacity of the lung for carbon monoxide; CHD$\mathrm{PAH}$ : congenital heart disease associated PAH. 
conferred a worse prognosis. This would be consistent with the findings from a UK-wide epidemiology study [17]. Patients with idiopathic, heritable, anorexigen-associated $\mathrm{PAH}$ are regarded as having similar outcomes as they share clinical and pathophysiological features [18]. Hence, the grouping of aetiologies in the SCS would be consistent with findings from previous studies. There is also increasing evidence to support a sex difference in patient outcome and this is confirmed by the present study. More females are affected by PAH than males but they have a better prognosis [4, 19]. Recent analysis of patients enrolled in REVEAL showed that men had a higher mean $P$ pa and mean $P$ ra at diagnosis and those aged $\geqslant 60 \mathrm{yrs}$ had lower survival rates compared with females aged $\geqslant 60 \mathrm{yrs}$ [20]. Sex hormones are thought to play a role but the precise mechanisms remain to be elucidated. The individual prognostic value of other component variables in the SCS has also been demonstrated in other studies (age [3, 19], 6MWD [4, 6, 21-25], Pra [6, 23-27], CO [4]).

Algorithms advising on the initial choice of drugs and the use of combination therapy advocated by current guidelines on PAH management are primarily based on WHO FC as its prognostic value has been firmly established [1, 28, 29]. However, WHO FC may not be a sufficiently reliable measure of functional status as wide variation in clinicians' assessment has been reported [30]. The differences between WHO FC I or II and IV are clear-cut, but WHO FC III encompasses patients with a wide range of functional capacity. The results of this study showed that the SCS could provide further risk stratification in WHO FC III patients and hence supplement WHO FC in clinical assessment. Variables measured during follow-up may be more predictive of long-term outcome than those measured at baseline evaluation as they would capture the impact of treatment response and disease progression on survival. A recent study has confirmed the prognostic impact of changes in outcome variables during the course of disease and demonstrated the importance of incorporating them into risk assessment [31], but there are currently no published prediction tools specifically developed to address this issue. We propose that the SCS could be used to assess the initial risk of mortality in the one to two year time horizons with a view to develop a risk score incorporating changes in mortality predictors over time for repeated use during follow-up.

This study has several limitations. Missing data were unavoidable due to the retrospective nature of the study. As measurements of NT-pro-BNP and CAMPHOR score were not introduced into clinical practice until 2004, there were fewer data compared with other baseline variables which may have introduced bias against them in multivariate survival analyses despite statistical adjustment. The derivation cohort consisted of patients with heterogeneous aetiologies of PAH with relatively small numbers in some subgroups. However, this simply reflects the relative incidence of different PAH aetiologies in a real-life clinical cohort. The data on vasoreactivity status at diagnosis were incomplete, so the effect of a positive vasodilatory response on survival could not be assessed. Only one patient demonstrated sustained response from $\mathrm{CCB}$ and was excluded from the study. This is based on the finding that long-term $\mathrm{CCB}$ responders have a better prognosis than non-CCB responders [32]. As the number is small, the bias associated with this exclusion would be insignificant. There were no patients with rarer causes of WHO Group I PAH such as schistosomiasis or chronic haemolytic anaemia in the derivation or validation cohort, and only patients with idiopathic and heritable PAH were included in the validation cohort. Hence, the performance of the SCS in other PAH subgroups is still to be validated. $17 \%$ of patients in the validation cohort did not have all the required variables to calculate the SCS. It was not possible to determine how the SCS would perform in these patients compared with other equations, but there was no difference in survival between patients with and without the SCS. Heart rate (HR) and systolic blood pressure (SBP) were measured in each patient at diagnosis but not recorded in the validation database and hence unavailable for this analysis. The REVEAL equation could not be included in the comparison as the systematic omission of HR and SBP data would lead to bias in its performance. This is a limitation of database analysis that does not reflect the potential value of an assessment tool in clinical practice.

In conclusion, the SCS is a simple multidimensional risk score combining the impact of demographics, pulmonary haemodynamics and functional status on survival in incident $\mathrm{PAH}$ patients. When validated in an independent UK idiopathic and heritable PAH cohort, it correlated with mortality and provided further risk stratification in WHO FC III patients. It may perform better in UK populations than prognostic equations derived from other registry studies but further validation in wider PAH populations is required before firm conclusions on its clinical utility can be made.

\section{STATEMENT OF INTEREST}

Statements of interest for W-T.N. Lee, K. Sheares, J. Pepke-Zaba, A.J. Peacock, M.K. Johnson and for the study itself can be found at www. erj.ersjournals.com/site/misc/statements.xhtml

\section{ACKNOWLEDGEMENTS}

The authors would like to thank J. Alsop (Numerus Ltd, Northampton, UK) for his statistical advice and Actelion UK for funding this project.

\section{REFERENCES}

1 Galie N, Hoeper MM, Humbert M, et al. Guidelines for the diagnosis and treatment of pulmonary hypertension: The Task Force for the Diagnosis and Treatment of Pulmonary Hypertension of the European Society of Cardiology (ESC) and the European Respiratory Society (ERS), endorsed by the International Society of Heart and Lung Transplantation (ISHLT). Eur Heart J 2009; 30: 2493-2537.

2 D'Alonzo GE, Barst RJ, Ayres SM, et al. Survival in patients with primary pulmonary hypertension. Results from a national prospective registry. Ann Intern Med 1991; 115: 343-349.

3 Thenappan T, Shah SJ, Rich S, et al. Survival in pulmonary arterial hypertension: a reappraisal of the NIH risk stratification equation. Eur Respir J 2010; 35: 1079-1087.

4 Humbert M, Sitbon O, Chaouat A, et al. Survival in patients with idiopathic, familial, and anorexigen-associated pulmonary arterial hypertension in the modern management era. Circulation 2010; 122: $156-163$.

5 Humbert M, Sitbon O, Yaïci A, et al. Survival in incident and prevalent cohorts of patients with pulmonary arterial hypertension. Eur Respir J 2010; 36: 549-555.

6 Benza RL, Miller DP, Gomberg-Maitland M, et al. Predicting survival in pulmonary arterial hypertension: insights from the Registry to Evaluate Early and Long-Term Pulmonary Arterial 
Hypertension Disease Management (REVEAL). Circulation 2010; 122: 164-172.

7 Benza RL, Gomberg-Maitland M, Miller DP, et al. The REVEAL risk score calculator in newly diagnosed patients with pulmonary arterial yypertension. Chest 2012; 141: 354-362.

8 Thenappan T, Glassner C, Gomberg-Maitland M. Validation of the pulmonary hypertension connection equation for survival prediction in pulmonary arterial hypertension. Chest 2012; 141: 642-650.

9 Quanjer PH, Tammeling GJ, Cotes JE, et al. Volumes pulmonaires et debits ventilatoires forces. Groupe de travail sur la standardisation des epreuves fonctionnelles respiratoires. Communaute Europeenne $\mathrm{du}$ Charbon et de l'Acier. Position officielle de l'European Respiratory Society [Lung volumes and forced ventilatory flows. Work Group on Standardization of Respiratory Function Tests. European Community for Coal and Steel. Official position of the European Respiratory Society]. Rev Mal Respir 1994; 11: Suppl. 3, 5-40.

10 Galie N, Torbicki A, Barst R, et al. Guidelines on diagnosis and treatment of pulmonary arterial hypertension. The Task Force on Diagnosis and Treatment of Pulmonary Arterial Hypertension of the European Society of Cardiology. Eur Heart J 2004; 25: 2243-2278.

11 McKenna SP, Doughty N, Meads DM, et al. The Cambridge Pulmonary Hypertension Outcome Review (CAMPHOR): a measure of health-related quality of life and quality of life for patients with pulmonary hypertension. Qual Life Res 2006; 15: 103-115.

12 Brier GW. Verification of forecasts expressed in terms of probability. Monthly Weather Review 1950; 78: 1-3.

13 Gerds TA, Cai T, Schumacher M. The performance of risk prediction models. Biom J 2008; 50: 457-479.

14 Dimopoulos $\mathrm{K}$, Inuzuka $\mathrm{R}$, Goletto $\mathrm{S}$, et al. Improved survival among patients with Eisenmenger syndrome receiving advanced therapy for pulmonary arterial hypertension. Circulation 2010; 121 20-25.

15 Kawut SM, Taichman DB, Archer-Chicko CL, et al. Hemodynamics and survival in patients with pulmonary arterial hypertension related to systemic sclerosis. Chest 2003; 123: 344-350.

16 Le PJ, Humbert M, Mouthon L, et al. Systemic sclerosis-associated pulmonary arterial hypertension. Am J Respir Crit Care Med 2010; 181: $1285-1293$.

17 Condliffe R, Kiely DG, Peacock AJ, et al. Connective tissue diseaseassociated pulmonary arterial hypertension in the modern treatment era. Am J Respir Crit Care Med 2009; 179: 151-157.

18 Souza R, Humbert M, Sztrymf B, et al. Pulmonary arterial hypertension associated with fenfluramine exposure: report of 109 cases. Eur Respir J 2008; 31: 343-348.

19 Kane GC, Maradit-Kremers H, Slusser JP, et al. Integration of clinical and hemodynamic parameters in the prediction of longterm survival in patients with pulmonary arterial hypertension. Chest 2011; 139: 1285-1293.
20 Shapiro S, Traiger GL, Turner M, et al. Sex differences in the diagnosis, treatment, and outcome of patients with pulmonary arterial hypertension enrolled in the Registry to Evaluate Early and Long-Term Pulmonary Arterial Hypertension Disease Management. Chest 2012; 141: 363-373.

21 McLaughlin VV, Sitbon O, Badesch DB, et al. Survival with firstline bosentan in patients with primary pulmonary hypertension. Eur Respir J 2005; 25: 244-249.

22 Miyamoto S, Nagaya N, Satoh T, et al. Clinical correlates and prognostic significance of six-minute walk test in patients with primary pulmonary hypertension. Comparison with cardiopulmonary exercise testing. Am J Respir Crit Care Med 2000; 161: 487-492.

23 Provencher S, Sitbon O, Humbert M, et al. Long-term outcome with first-line bosentan therapy in idiopathic pulmonary arterial hypertension. Eur Heart J 2006; 27: 589-595.

24 Sitbon $\mathrm{O}$, Humbert $\mathrm{M}$, Nunes $\mathrm{H}$, et al. Long-term intravenous epoprostenol infusion in primary pulmonary hypertension: prognostic factors and survival. I Am Coll Cardiol 2002; 40: 780-788.

25 van Wolferen SA, Marcus JT, Boonstra A, et al. Prognostic value of right ventricular mass, volume, and function in idiopathic pulmonary arterial hypertension. Eur Heart J 2007; 28: 1250-1257.

26 Sandoval J, Bauerle O, Palomar A, et al. Survival in primary pulmonary hypertension. Validation of a prognostic equation. Circulation 1994; 89: 1733-1744.

27 McLaughlin VV, Shillington A, Rich S. Survival in primary pulmonary hypertension: the impact of epoprostenol therapy. Circulation 2002; 106: 1477-1482.

28 McLaughlin VV, Archer SL, Badesch DB, et al. ACCF/AHA 2009 expert consensus document on pulmonary hypertension: a report of the American College of Cardiology Foundation Task Force on Expert Consensus Documents and the American Heart Association: developed in collaboration with the American College of Chest Physicians, American Thoracic Society, Inc., and the Pulmonary Hypertension Association. Circulation 2009; 119: 2250-2294.

29 National Pulmonary Hypertension Centres of the UK, Ireland. Consensus statement on the management of pulmonary hypertension in clinical practice in the UK and Ireland. Thorax 2008; 63: Suppl. 2, ii1-ii41.

30 Taichman DB, McGoon MD, Harhay MO, et al. Wide variation in clinicians' assessment of New York Heart Association/World Health Organization functional class in patients with pulmonary arterial hypertension. Mayo Clin Proc 2009; 84: 586-592.

31 Nickel N, Golpon H, Greer M, et al. The prognostic impact of follow-up assessments in patients with idiopathic pulmonary arterial hypertension. Eur Respir J 2012; 39: 589-596.

32 Sitbon $\mathrm{O}$, Humbert $\mathrm{M}$, Jais $\mathrm{X}$, et al. Long-term response to calcium channel blockers in idiopathic pulmonary arterial hypertension. Circulation 2005; 111: 3105-3111. 